\title{
Enhanced biodiversity beyond marine reserve boundaries: The cup spillith over
}

\author{
Garry R. Russ ${ }^{1,3}$ and Angel C. Alcala ${ }^{2}$ \\ ${ }^{1}$ School of Marine and Tropical Biology and ARC Centre for Coral Reef Studies, James Cook University, \\ Townsville, Queensland 4811 Australia \\ ${ }^{2}$ Silliman University Angelo King Center for Research and Environmental Management, Silliman University, \\ Dumaguete City, 6200, Philippines
}

\begin{abstract}
Overfishing can have detrimental effects on marine biodiversity and the structure of marine ecosystems. No-take marine reserves (NTMRs) are much advocated as a means of protecting biodiversity and ecosystem structure from overharvest. In contrast to terrestrial protected areas, NTMRs are not only expected to conserve or recover biodiversity and ecosystems within their boundaries, but also to enhance biodiversity beyond their boundaries by exporting species richness and more complex biological communities. Here we show that species richness of large predatory reef fish increased fourfold and 11-fold inside two Philippine no-take marine reserves over 14 and 25 years, respectively. Outside one reserve (Apo) the species richness also increased. This increase beyond the Apo reserve boundary was $78 \%$ higher closer to the boundary $(200-250 \mathrm{~m})$ than farther from it $(250-500 \mathrm{~m})$. The increase in richness beyond the boundary could not be explained by improvements over time in habitat or prey availability. Furthermore, community composition of predatory fish outside but close to $(200-250 \mathrm{~m})$ the Apo reserve became very similar to that inside the reserve over time, almost converging with it in multivariate space after 26 years of reserve protection. This is consistent with the suggestion that, as community composition inside Apo reserve increased in complexity, this complexity spilled over the boundary into nearby fished areas. Clearly, the spillover of species richness and community complexity is a direct consequence of the spillover of abundance of multiple species. However, this spillover of species richness and community complexity demonstrates an important benefit of biodiversity and ecosystem export from reserves, and it provides hope that reserves can help to reverse the decline of marine ecosystems and biodiversity.
\end{abstract}

Key words: biodiversity benefits; community complexity; coral reef fish; ecosystem export; marine reserves; Philippines; predatory reef fish; species richness; species spillover.

\section{INTRODUCTION}

Overharvest can reduce biodiversity and alter the structure of marine ecosystems (Dayton et al. 1995, Estes and Duggins 1995, Jennings and Kaiser 1998, Pauly et al. 1998, Pinnegar et al. 2000). Overharvest has degraded marine ecosystems on a global scale (Jackson et al. 2001, Pauly et al. 2002, Roberts 2007, Halpern et al. 2008). The worldwide depletion of predatory fish is a well documented example of such degradation, with rapid declines in abundance and diversity (Myers and Worm 2003), resulting in loss of ecosystem stability (Myers et al. 2007) and important biodiversity and ecosystem services (Worm et al. 2006).

No-take marine reserves (NTMRs) are a much advocated solution for protecting biodiversity and ecosystem structure from overharvest (Bohnsack and Ault 1996, Dayton et al. 2000, Pinnegar et al. 2000,

Manuscript received 2 July 2009; revised 23 February 2010; accepted 25 February 2010. Corresponding Editor: P. K. Dayton.

${ }^{3}$ E-mail: garry.russ@jcu.edu.au
Sobel and Dahlgren 2004, Lester et al. 2009). NTMRs are now seen as a key tool in managing marine ecosystems, protecting exploited species and restoring natural states of biodiversity (Côté et al. 2001, Sala et al. 2002, Halpern 2003, Sobel and Dahlgren 2004, Lester et al. 2009, Molloy et al. 2009). NTMRs are usually established with one or both of two objectives - fisheries management and conservation (Hastings and Botsford 2003, Sobel and Dahlgren 2004).

For fisheries management purposes, NTMRs enhance portions of the spawning stocks of exploited species within them (Dayton et al. 2000, Côté et al. 2001, Halpern 2003, Lester et al. 2009, Molloy et al. 2009). This provides an insurance policy against failure of more conventional fisheries management techniques applied outside the NTMRs (Bohnsack 1998). It is hoped also that the NTMRs will become net exporters of biomass of exploited species, either by relocation of adults (spillover) or export of recruits (recruitment subsidy) to fished areas (Russ 2002, Roberts et al. 2005, Sale et al. 2005). Several studies have demonstrated spillover of abundance and biomass of adults of fished species from 

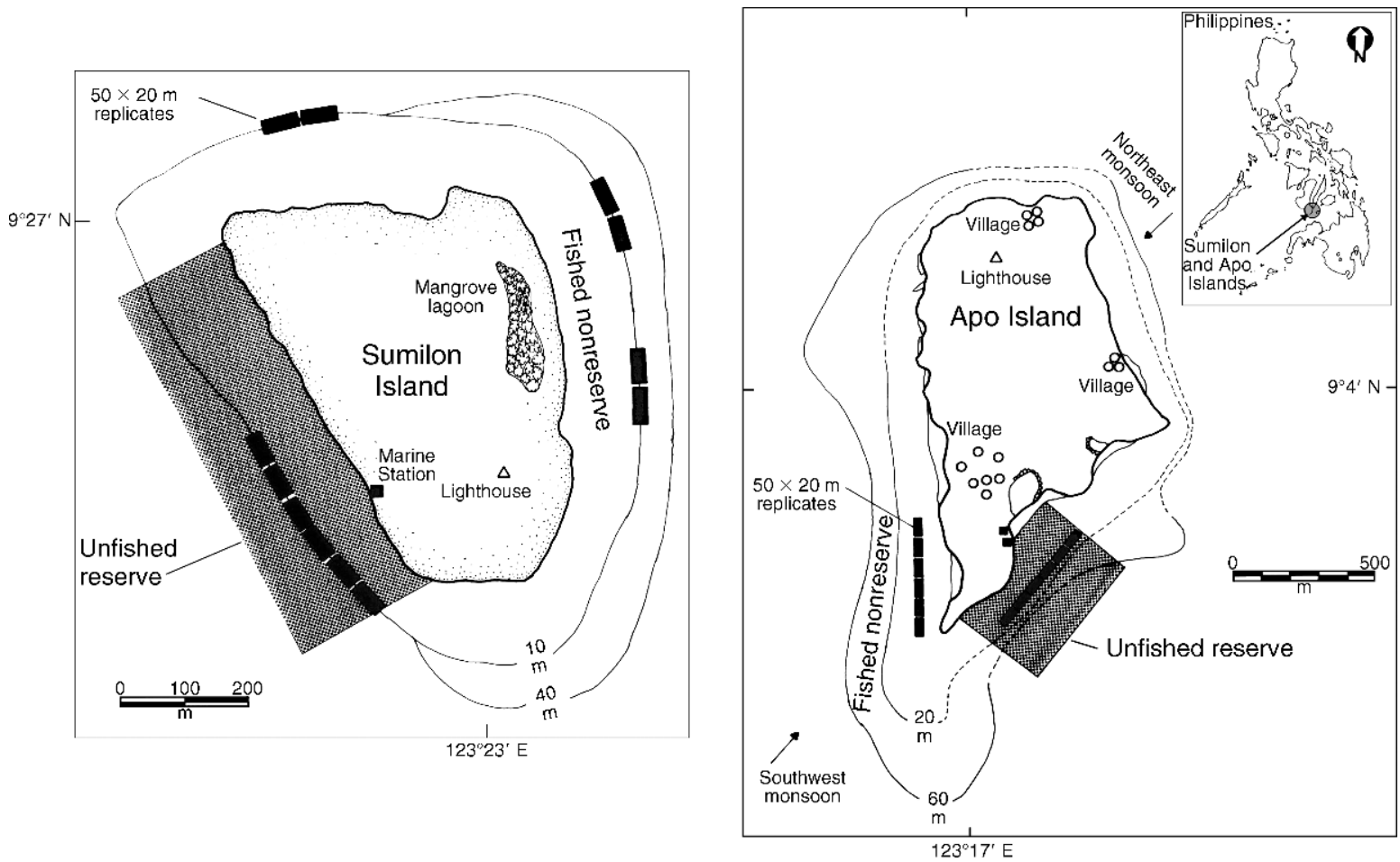

FIG. 1. Map showing location of Sumilon and Apo Islands, central Philippines and location of the no-take reserve areas (shaded) and the fished nonreserve areas. The positions of the six $50 \times 20 \mathrm{~m}$ replicate underwater visual census plots surveyed at each sampling site and time are shown.

reserves, and maintenance of fishery catches near reserve boundaries (e.g., McClanahan and Kaunda-Arara 1996, Russ and Alcala 1996, McClanahan and Mangi 2000, Roberts et al. 2001, Gell and Roberts 2003, Russ et al. 2004, Alcala et al. 2005). Larval export from marine reserves has recently been inferred (Cudney-Bueno et al. 2009, Pecl et al. 2009) and demonstrated unequivocally for the first time (Planes et al. 2009).

For conservation purposes NTMRs protect species, communities, biodiversity, and ecosystems inside reserves (Babcock et al. 1999, 2010, Castilla 1999, Pinnegar et al. 2000, Côté et al. 2001, Micheli et al. 2004, Lester et al. 2009). Somewhat akin to terrestrial national parks, NTMRs aim to maintain or recover biodiversity and ecosystems in natural states inside them. Marine reserves have enhanced recovery of marine ecosystems in rocky intertidal areas of Chile (Castilla 1999), subtidal kelp forests in New Zealand (Babcock et al. 1999, 2010), California (Behrens and Lafferty 2004, Babcock et al. 2010), and Australia (Edgar et al. 2009, Babcock et al. 2010), and coral reefs in Kenya (McClanahan and Shafir 1990, McClanahan and Graham 2005, Babcock et al. 2010) and the Bahamas (Mumby et al. 2006). However, rarely is export of enhanced biodiversity an explicit objective of NTMRs. Rather, such export is more of a nebulous hope, an added benefit of NTMRs. Spatial gradients of declining species richness of reef fish across reserve boundaries have been reported at single points in time by a few studies (McClanahan and Mangi 2000, Kaunda-Arara and Rose 2004). One study suggested, based on observations at one point in time, that a reserve may have had community-wide effects beyond its boundaries (Guidetti 2006). These static observations are consistent with spillover of species richness and community complexity from no-take reserves. To date, no study has demonstrated the development of such a process over time.

The aim of this study is to test if NTMRs can, over time, enhance species richness and community complexity beyond their boundaries. We show not only a dramatic increase in species richness of predatory coral reef fish over 25 years in NTMRs in the Philippines, but also that one of these NTMRs is supplementing species richness and community complexity beyond its boundaries. The study provides an empirical demonstration of the development over time of diversity spillover and also suggests that no-take reserves can export more complex communities beyond their boundaries.

\section{Methods \\ Study sites}

The study was carried out at two islands in the central Visayas region of the Philippines (Fig. 1). The islands were Sumilon Island, southeast of Cebu $\left(9^{\circ} 21^{\prime} \mathrm{N}\right.$, $123^{\circ} 23^{\prime}$ E) and Apo Island, southeast of Negros $\left(9^{\circ} 4^{\prime}\right.$ 
N, $123^{\circ} 16^{\prime}$ E) (Alcala and Russ 2006). Sumilon and Apo Islands had no-take marine reserves established in 1974 and 1982, respectively. Detailed descriptions of the study sites and their management histories are provided in Russ and Alcala (2003) and Alcala and Russ (2006). The management histories of the four sites (two reserves, two fished control sites) over the 25-year period (1983-2008) provided a unique natural experiment to investigate the effects of marine reserve protection and fishing on the species richness and community composition of large predatory reef fish.

\section{Method of visual census}

Quantitative estimates of species richness (number of species per unit area) and density of predatory coral reef fishes were made at the two no-take reserves and the two nonreserve (control) sites (Fig. 1) using a technique of underwater visual census (UVC; Russ and Alcala 2003). Six replicate $50 \times 20 \mathrm{~m}$ censuses were made by the same observer (GRR) on the reef slopes of each reserve and control site in December or November for 19 of 25 years from 1983 to 2008 (Fig. 1). Surveys spanned 3-17 m depth at Sumilon reserve, 6-17 $\mathrm{m}$ at Apo reserve, and 9$17 \mathrm{~m}$ at the two nonreserve (fished) sites. A detailed account of the method of visual census is provided in Russ and Alcala (2003). The same replicate areas were surveyed at each site in each sampling year (Fig. 1). Forty-seven taxa were recorded in the families Serranidae (Epinephelinae) (23 species), Lutjanidae (15 species), and Lethrinidae ( 9 species; Table 1). These taxa were designated as a group of "large predators." Data were expressed as the mean number of species of large predatory reef fish per $1000 \mathrm{~m}^{2}$, calculated from the $n=6$ replicates surveyed at each site and time. Juveniles (less than $10 \mathrm{~cm}$ total length) were not recorded.

At Sumilon no-take reserve the complex management history (Alcala and Russ 2006) allowed 19 UVC estimates of fish species richness at reserve ages of -3 (fished for three years after reserve status removed) to 14 years. At Apo, 19 estimates were made at no-take reserve ages of 1 to 26 years. Species richness estimates for nonreserves were made within days of sampling the reserves. Data collected at Sumilon nonreserve in the years 1988-1992 were not used as "fished controls" since this site was either closed to fishing (1987-1991) or had just been reopened to fishing (1992) after a five year fishing closure (Russ and Alcala 2003). Negative years of protection at Sumilon reserve indicate years open to fishing following closures, caused by the complex management history of this reserve (Russ and Alcala 2003).

Most sampling at Sumilon nonreserve occurred $>400$ $\mathrm{m}$ from Sumilon reserve (Fig. 1), making spillover detection difficult. Spatial distribution of fish species richness and density over time at the Apo nonreserve site was estimated using the methods described in Russ and Alcala (1996). The six $50 \times 20 \mathrm{~m}$ replicates in the Apo nonreserve began $\sim 200 \mathrm{~m}$ from the southern boundary of the Apo reserve (Fig. 1; Russ and Alcala 1996).
TABLE 1. The taxa of "large predatory coral reef fish" (families Serranidae [Epinephelinae; 23 species], Lethrinidae [9 species], and Lutjanidae [15 species]) recorded in this study.

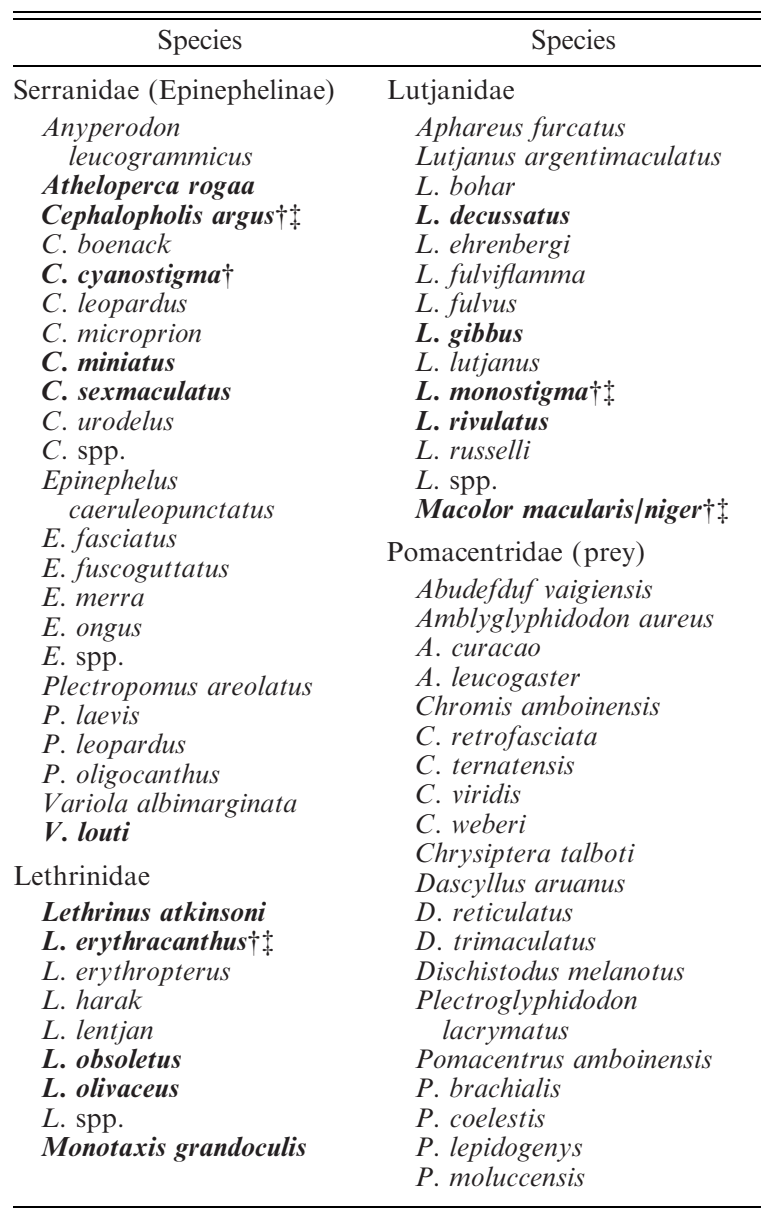

Notes: Also shown are the 20 species of Pomacentridae used to construct a "prey index" at the Apo nonreserve site. The 16 species of predatory fish used in the multidimensional scaling analysis are shown in boldface type.

$\dagger$ The five species of large predatory reef fish detected by similarity percentage analysis that contributed most to the dissimilarity in community composition at Apo Reserve between the periods $1983-1993$ and $2000-2008$, that is, contributed most to the community recovery over time.

$\$$ Four of the top five species of large predatory reef fish detected by similarity percentage analysis that contributed most to the similarity in community composition between Apo reserve and the Apo nonreserve replicate closest to the reserve in the period 2000-2008 (see Fig. 3).

Estimates of species richness were made for each of these six replicates in the Apo nonreserve area. Since each replicate was separated by only $5-10 \mathrm{~m}$, the distances of each replicate from the southern boundary of the reserve ranged from approximately $200-250 \mathrm{~m}$ (replicate 1$)$ to 450-500 m (replicate 6; Fig. 1). The species richness estimates $(n=6)$ were averaged for each site and year to express long-term changes in species richness over time. At Apo nonreserve, species richness data were also calculated separately for replicate 1 , the replicate closest to the reserve boundary (200-250 m from boundary) 
and compared with the average for replicates 2-6 (250$500 \mathrm{~m}$ from reserve boundary), the most distant replicates from the reserve boundary. All of these data (replicate 1 vs. average of replicates 2-6) were then averaged for the periods 1983-1993 (early phase of reserve protection), 1994-1999 (mid phase of reserve protection), and 2000-2008 (late phase of reserve protection) to examine how species richness at Apo nonreserve changed in space (replicate 1 vs. average of replicates 2-6) and over time (1983-2008).

The condition of the benthic habitat for each site and time was expressed as a single habitat complexity index (HCI) (Russ et al. 2005, Abesamis et al. 2006b): HCI = (proportion of live hard coral cover +1$) \times$ (mean rugosity +1$) \times($ mean reef steepness +1$)$. This index ranges from 1 to 50 . Higher values indicate steeper reef faces with high hard coral cover and rugosity. Lower values indicate relatively flat expanses of sand, rubble, or rock, with low hard coral cover. Details of the methods used to estimate HCI at the four sites over time are provided in Russ et al. (2005).

A prey abundance index calculated for Apo nonreserve was density of 20 of the most common species of damselfish (Pomacentridae; see Table 1), estimated by UVC when predator species richness was estimated. Due to their high numerical abundance pomacentrid species were placed into $\log _{4}$ abundance categories (category $1=$ 1 fish, $2=2-4$ fish, $3=5-16$ fish, $4=17-64$ fish, $5=65-$ 256 fish, $6=257-1024$ fish, $7=1025-4096$ fish, $8=4097-$ 16384 fish). The midpoint of each category was taken as the best estimate of density, except for category 8 , where the minimum of the category was taken as the best estimate of density.

\section{Data analysis}

Species richness, the number of species per unit area, is used here as a simple measure of biodiversity. To confirm that species richness was an effective index of diversity, that is richness and diversity were positively and strongly correlated, we calculated Shannon Weaver diversity indices $\left(\mathrm{H}^{\prime}\right)$ of large predatory reef fish for each replicate at each site and time. We then determined simple relationships between $\mathrm{H}^{\prime}$ and $\log _{2}$ (number of species) (Stirling and Wilsey 2001) for each of the four sites. For each site the number of species in a replicate (range $0-12$ ) was plotted against a $\mathrm{H}^{\prime}$ calculated for the same number of species but randomly selected from a collection of $\mathrm{H}^{\prime}$ values from another site. This ensured independence in the data used to determine the relationships. All relationships were highly significant $(P<0.001)$ with mean $r^{2}$ for the four relationships 0.96 (range 0.91-0.99). Thus species richness was an excellent proxy for species diversity. This result is consistent with a meta-analysis of studies where total number of species ranged from $>10$ and $<100$ (Stirling and Wilsey 2001), a range into which our study falls $(n=47)$.

Relationships between mean species richness and years of reserve protection (reserve age) were described by linear regression (Sumilon and Apo reserves, Sumilon nonreserve) and a second-order polynomial (Apo nonreserve). A univariate, repeated measures analysis of variance was performed on species richness data $\left(\log _{10^{-}}\right.$ transformed) for Sumilon and Apo islands separately. The factors in these analyses were reserve status (two levels: no-take reserve or fished nonreserve) and the repeated measure time (19 repeat times from 1983 to 2008 at Apo, 15 repeat times at Sumilon over the same period but eliminating 1988-1992 data when Sumilon nonreserve was closed to fishing). Relationships between mean $\mathrm{HCI}$ and reserve age were described by linear regression. To correct for effects of slight habitat improvement at Apo nonreserve (significant temporal increase in $\mathrm{HCI}$ ) we performed a repeated measures analysis of covariance (covariate $=\mathrm{HCI}$ ). We used Greenhouse-Geisser adjusted $P$ values in the repeated measures analyses of variance. For all repeated measures analyses of variance and repeated-measures analyses of covariance, the data were examined for homogeneity of variance (Cochrans test at $P<0.05$ ), skewness and outliers (box plots), normality, and correlations between means and variances.

At Apo nonreserve we compared species richness close to the reserve boundary (200-250 m, replicate 1) with that far from the boundary $(250-500 \mathrm{~m}$, mean of replicates 2-6) in early (1983-1993), mid (1994-1999), and late (2000-2008) periods of reserve protection by chi-square. Although somewhat arbitrary, these time periods had almost equal numbers of sampling years. Factor changes over time (1983-1993 average values vs. 2000-2008 average values) close to $(200-250 \mathrm{~m})$ compared to far from $(250-500 \mathrm{~m})$ the boundary at Apo nonreserve for species richness of predatory fish, $\mathrm{HCI}$ and the prey abundance index were calculated, and expressed as a percent change.

Multidimensional scaling was used to investigate changes over time in community composition of large predatory fish at three sites at Apo Island: Apo reserve, Apo nonreserve close to (200-250 m) the Apo reserve boundary, and Apo nonreserve far from (250-500 m) the Apo reserve boundary. For this analysis the study was divided arbitrarily into six approximately equal times: $1=1983-1990,2=1991-1993,3=1994-1997,4=$ $1998-2000,5=2001-2004,6=2006-2008$. The multidimensional scaling analysis was based on UVC estimates of density (number/1000 $\mathrm{m}^{2}$ ) of the 16 most abundant species of large predatory reef fish at Apo Island during the study (see Table 1). For the multidimensional scaling, density data for each site were averaged across all replicates and sampling years within time periods. $\log (x+1)$-transformed density values for each species at each site and time were used and the resemblance matrix for the multidimensional scaling was based on the Bray-Curtis similarity measure. We used similarity percentage analysis to identify which species accounted most for similarities or dissimilarities of groups identified by the multidimensional scaling. 

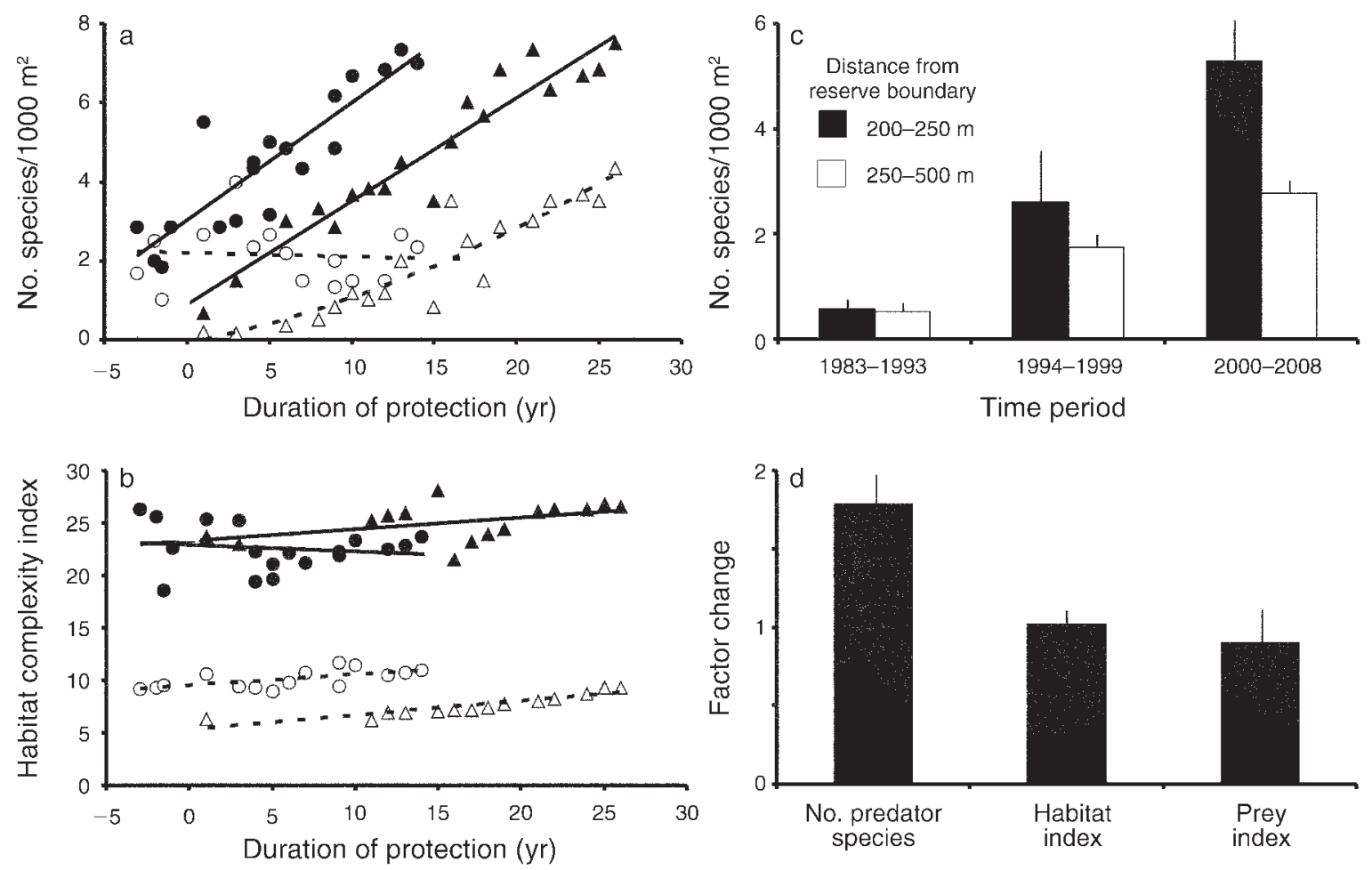

FIG. 2. Temporal patterns of species richness at reserve and nonreserve sites. (a) Species richness of large predatory reef fish vs. duration of reserve protection for reserves (solid lines) and nonreserves (dashed lines). Key to symbols: solid circles, Sumilon reserve (SR); open circles, Sumilon nonreserve (SNR); solid triangles, Apo reserve (AR); open triangles, Apo nonreserve (ANR). (b) Relationships between mean habitat complexity index (HCI) and duration of protection. All symbols are the same as for panel (a). (c) Species richness of large predatory reef fish at ANR close to $(200-250 \mathrm{~m})$ and far from $(250-500 \mathrm{~m})$ the AR boundary at three time periods. Error bars depict + SE. (d) Factor change over time (1983-1993 vs. 2000-2008 average values) close to (200-250 m) compared to far from $(250-500 \mathrm{~m})$ the boundary at ANR for species richness of predatory fish, HCI, and prey index.

Multidimensional scaling and similarity percentage analyses were run in PRIMER (Plymouth routines in multivariate ecological research) version 6 software (Clark and Gorley 2006).

\section{RESUlts}

Positive relationships between mean species richness and years of reserve protection (Fig. 2a) occurred for Sumilon reserve (linear, $r^{2}=0.78, P<0.001$ ), Apo reserve (linear, $r^{2}=0.92, P<0.001$ ), and Apo nonreserve (second-order polynomial, $r^{2}=0.86, P<$ 0.001). At Sumilon reserve, species richness increased fourfold over two separate periods of protection of 9 and 14 years, with no significant change outside the reserve (Fig. 2a). A univariate, repeated measures analysis of variance indicated a significant reserve $\times$ time interaction at Sumilon $\left(F_{14,140}=3.30, P<0.001\right.$, Fig. 2a). Thus no-take protection likely caused the increase in species richness inside Sumilon Reserve. At Apo reserve, species richness increased 11-fold over 26 years of continuous no-take protection, with a clear, but more moderate and initially slower, increase outside the reserve over time (Fig. 2a). The increases in species richness inside the two reserves could not be accounted for by improvements in habitat (Fig. 2b). A slight, but significant improvement in habitat over time occurred at Apo nonreserve (significant temporal increase in habitat complexity index (HCI), $r^{2}=0.82, P<0.001$, Fig. $2 b$ ). When increases in species richness of predatory fish over time at Apo nonreserve were corrected for this slight habitat improvement at Apo nonreserve it was clear that no-take protection caused the substantial increase in species richness inside Apo reserve (repeated-measures analysis of covariance [covariate $=\mathrm{HCI}$ ], significant reserve $\times$ time interaction $\left[F_{9,81}=10.68, P<0.001\right.$, Fig. $2 a, b])$.

Species richness clearly increased over time at Apo nonreserve, open to fishing (Fig. 2a). This improvement was much greater closer to $(200-250 \mathrm{~m})$ than further from $(250-500 \mathrm{~m})$ the reserve boundary over time (Fig. 2c). At Apo nonreserve, species richness close to the reserve boundary did not differ from that far from the boundary in early (1983-1993) and mid-periods (19941999) of reserve protection (Fig. 2c, chi-square $P>$ 0.05). However, a significant difference in species richness between the areas close to and far from the boundary did occur in the late period (2000-2008) of reserve protection (Fig. 2c, chi-square $=4.89, P<0.05$ ). There was no evidence that fishers at Apo Island fished less in the areas close to $(100-300 \mathrm{~m})$ than in areas 


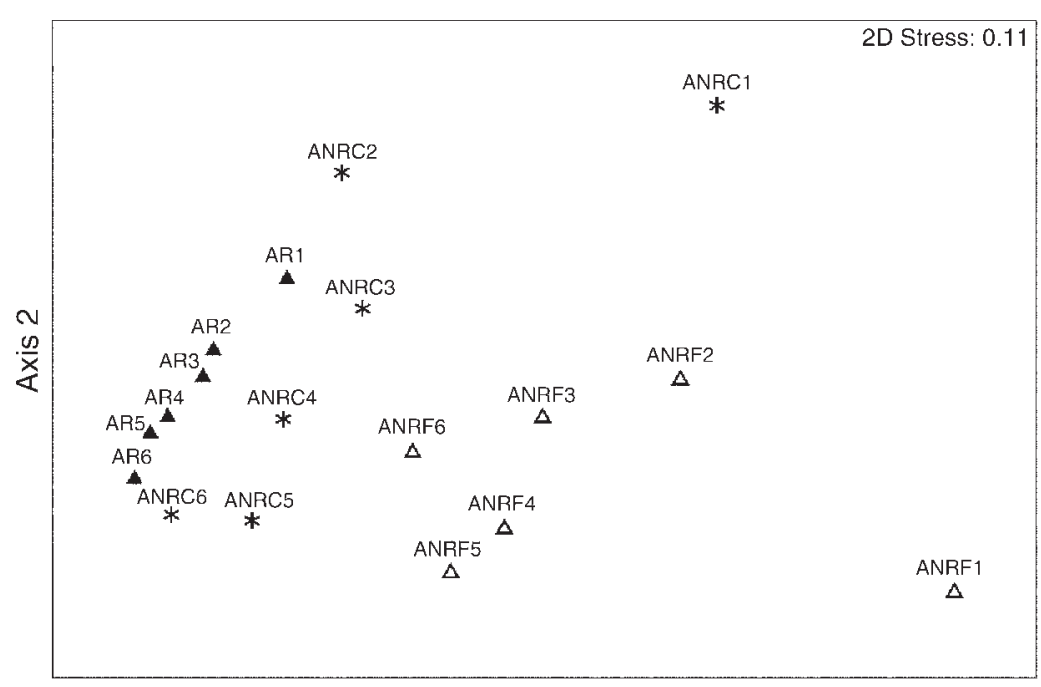

Axis 1

FIG. 3. Results of a multidimensional scaling analysis of community composition of large predatory reef fish over time at three sites: solid triangles, Apo reserve (AR); asterisks, Apo nonreserve close to (200-250 m) the AR boundary (ANRC); open triangles, Apo nonreserve far from (250-500 m) the AR boundary (ANRF). The six times are: 1, 1983-1990; 2, 1991-1993; 3, 1994-1997; 4, 1998-2000; 5, 2001-2004; 6, 2006-2008. The analysis was based on the 16 most abundant species of large predatory reef fish at Apo Island during the study (see Table 1).

further from $(>300 \mathrm{~m})$ the Apo reserve boundaries (Abesamis et al. 2006a). The increase in species richness from early to late periods of protection for the area close to $(200-250 \mathrm{~m})$ the boundary was $78 \%$ greater than that far from the boundary $(250-500 \mathrm{~m})$ for species richness of predatory fish, $3 \%$ for HCI, and $-9 \%$ for prey abundance (Fig. 2d). Thus, species richness near the boundary did not increase due to improvements in habitat or prey availability. On the contrary, a $78 \%$ increase over time in species richness of predatory fish in the area closest to the reserve boundary was associated with a $9 \%$ decrease over time in abundance of prey.

The community composition of large predatory reef fish in the first seven years of the study (1983-1990) was quite distinct at all three sites at Apo Island: Apo reserve, Apo nonreserve close to the Apo reserve boundary, and Apo nonreserve far from the boundary (Fig. 3). Species richness was relatively low at Apo nonreserve and to a lesser extent Apo reserve, for much of this time (Fig. 2a), so differences among the three sites largely reflected chance sightings of rare species. Community composition changed substantially at all three sites over time (Fig. 3), with communities becoming more species rich (Fig. 2a, c) and complex due to protection from fishing (Apo reserve) and due to spillover and changes in fishing practices (Apo nonreserve). Community composition at Apo nonreserve close to $(200-250 \mathrm{~m})$ the Apo reserve boundary became very similar to that inside the reserve over time, almost converging with it in multivariate space by 2006-2008 (Fig. 3). The community composition at Apo nonreserve far from $(250-500 \mathrm{~m})$ the Apo reserve boundary became more similar to that in the reserve over time, but remained distinct from the reserve composition in multivariate space even in 2006-2008 (Fig. 3). Four of the top five species that accounted for the community recovery over time inside the Apo reserve were also in the top five species that accounted for most of the similarity between Apo reserve and Apo nonreserve close to the reserve boundary in 2006-2008 (Table 1). This is consistent with the suggestion that as community composition inside Apo reserve increased in complexity over time, this community complexity spilled over the boundary into nearby fished areas.

\section{DisCusSION}

This study documents the development of spillover of species richness and community complexity from a notake marine reserve. The prerequisite for such spillover is enhanced species richness and community complexity inside reserves relative to fished areas. Enhanced species richness and community complexity inside reserves is reasonably well documented (e.g., Pinnegar et al. 2000, Côté et al. 2001, Halpern 2003, Micheli et al. 2004, Lester et al. 2009). In the present study, species richness of large predatory reef fish increased 4- to 11-fold over durations of no-take protection of 14-26 years (Fig. 2a). No such increase was detected in the fished control site at Sumilon Island, but a very clear increase was detected in the fished control site at Apo Island (Fig. 2a). This increase in species richness of predatory fish in the fished site at Apo Island was much greater closer to than further from the Apo reserve boundary. This spatial bias in species richness in the fished site developed over time and was not caused by improvements in habitat or prey availability (Fig. 2b-d).

Spillover of species richness was not detected at Sumilon reserve for several reasons. The replicates 
sampled in the nonreserve at Sumilon Island (Fig. 1) were selected as fished controls, well away from the reserve. The sampling was not designed to detect spillover. Thus, most sampling at Sumilon nonreserve occurred $>400 \mathrm{~m}$ from Sumilon reserve (Fig. 1), making spillover detection difficult. In addition, the nonreserve replicates at Sumilon closest to the reserve (at the northern end of the island; see Fig. 1) were separated from the reserve by a distinct discontinuity of benthic habitat, changing from steep hard coral slope to sandy slope. This habitat discontinuity also made detection of spillover problematic. More replicates were not placed at the northern and southern ends of the island initially because these areas are subject to very strong tidal currents. Note that the placement of the six adjacent nonreserve replicates at Apo Island, starting about 200 $\mathrm{m}$ from the southern Apo reserve boundary (Fig. 1), was also not a sampling design implemented to detect spillover (Russ and Alcala 1996). The nonreserve replicates at Apo were selected as fished controls with relatively similar habitat to the reserve and as a site offering some shelter from prevailing winds. The nonreserve replicates were placed, by chance, close enough to the southern boundary of the Apo reserve to detect spillover. Detection of spillover was enhanced since these nonreserve replicates are linked to the reserve by continuous hard coral reef slope. The detection of spillover of species richness at Apo reserve is likely to be a general phenomenon (applicable to many other reserves), provided that there is habitat continuity from reserve to nonreserve, and continuous transects are established across reserve boundaries to detect gradients.

We have previously reported that abundance of large predatory reef fish was spilling over from Apo reserve to the same fished nonreserve site after a decade of protection (Russ and Alcala 1996). We also reported that the mean number of species of large predatory reef fish had increased significantly inside and outside the Apo reserve after a decade of protection (Fig. 2 of Russ and Alcala [1996]). However, there was not a greater increase in species richness closer to than further from the reserve boundary after a decade of reserve protection (the period 1983-1993 in Fig. 2c). The present study shows that after 15 years of further no-take protection, enhanced species richness of predatory reef fish could be detected closer to than further from the reserve boundary at Apo nonreserve. These observations are consistent with a spatially limited (200-250 m) and very gradual (over 25 years) enhancement of species richness beyond the reserve boundary as species richness increased inside the reserve. Clearly, the spillover of species richness is a direct consequence of the spillover of abundance of multiple species. It is also clear that spillover of species richness will take longer to detect statistically than spillover of abundance of multiple or individual species.
Note that underwater visual census (UVC) will underestimate the potential significance of spillover of fish from reserves to adjacent fished areas (Russ and Alcala 1996). UVC will only detect fish in excess of those previously caught by fishers. The first effect detected if adult fish are being exported from a reserve should be an increase in catch rate just outside the reserve boundary (Russ 2002, Gell and Roberts 2003). In the case of diversity spillover, an increase in the species richness of the catch would be expected. Enhanced catch rates outside a reserve may induce increased fishing effort near the reserve boundary. This could potentially eliminate or reduce any increase in species richness just outside the reserve that could be detected by UVC. In this study, fishing clearly did not eliminate an increase in species richness just outside $(200-250 \mathrm{~m})$ the reserve boundary, but it could have reduced it. Abesamis et al. (2006a) quantified fishing effort at different distances from the Apo reserve. They showed that fishing effort was much lower within $100 \mathrm{~m}$ of the boundary than it was at distances of 100-300 $\mathrm{m}$ and greater. They concluded that this represented the equivalent of a $100-\mathrm{m}$ buffer zone around the no-take reserve that was self-imposed by the fishers. Fishers did not want to be accused of poaching, so they deliberately did not fish very close to the reserve boundary. However, fishing pressure was relatively high at distances of 100-300 m from both northern and southern reserve boundaries, and much greater also at more distant fishing grounds (Abesamis et al. 2006a). The 100-300 m distance encompasses that over which the present study has detected an increase over time in species richness and community complexity, and is thus consistent with spillover of diversity.

The development over 18-20 years (1983-2001, 19832003) of greater density and biomass closer to (200-250 $\mathrm{m})$ than further from the southern boundary of Apo reserve has also been reported for two other families of reef fish (surgeonfish and jacks) that account for 40-75\% of the fishery yield at Apo island (Russ et al. 2004), and for the large planktivorous surgeonfish Naso vlamingii (Abesamis and Russ 2005). Thus, gradients from higher to lower abundance just outside the southern boundary of Apo reserve have now developed over time for five families of reef fish. Furthermore, static (one point in time) gradients of declining reef fish density out to 200 $300 \mathrm{~m}$ have been detected across both southern and northern boundaries of Apo reserve (Abesamis et al. 2006b). This latter study surveyed 96 species (in 13 families) of reef fish targeted by fishing. Clearly, gradients of declining abundance of multiple species across the Apo reserve boundaries are consistent with results in this paper of increasing species richness developing over time just outside the southern reserve boundary.

The spillover reported here could be due to densityindependent fluxes and density-dependent relocation from reserve to nonreserve sites by multiple species. 
The various mechanisms causing spillover have been reviewed by Rakitin and Kramer (1996), Kaunda-Arara and Rose (2004), Abesamis and Russ (2005), and Abesamis et al. (2006b). An increasing number of studies have demonstrated spillover of abundance and biomass of exploited species from reserves (e.g., McClanahan and Kaunda-Arara 1996, Russ and Alcala 1996, Gell and Roberts 2003, Russ et al. 2004, Abesamis et al. 2006b). Other studies have reported maintenance or improvement of fishery catches near reserve boundaries and suggested that this was partly due to spillover (e.g., McClanahan and Kaunda-Arara 1996, McClanahan and Mangi 2000, Roberts et al. 2001, Russ et al. 2004, Alcala et al. 2005, Abesamis et al. 2006a).

Given that enhanced species richness and diversity inside no-take reserves has been reasonably well documented (Pinnegar et al. 2000, Côté et al. 2001, Halpern 2003, Micheli et al. 2004, Lester et al. 2009), how likely is it that such enhancement affects adjacent areas open to fishing? Empirical evidence for this is surprisingly sparse. Two studies of Kenyan no-take reserves have documented static (one point in time) spatial gradients of declining species richness of reef fish just outside marine reserve boundaries (McClanahan and Mangi 2000, Kaunda-Arara and Rose 2004). As indicated above, the only previous evidence of the development over time of enhanced species richness beyond a no-take reserve boundary was the study of Russ and Alcala (1996) at Apo reserve.

In addition to enhanced species richness and diversity, evidence exists for recovery of biological communities and ecosystems inside no-take marine reserves. Most of the well documented cases of community and ecosystem recovery involve long-term (decadal scale) studies (Babcock et al. 2010). Rocky inter-tidal reserves in Chile caused recovery of an exploited carnivorous muricid gastropod, subsequent decline of its prey, a mussel that competitively dominated hard substrata, recovery of abundance of two species of barnacles and two species of herbivorous keyhole limpets, and a consequent reduction in cover of macro-algae (Castilla 1999). Increased abundance of predatory lobsters and reef fish inside no-take reserves in New Zealand, California and Australia caused declines in kelp-eating urchins and subsequent recovery of kelp forests (Babcock et al. 1999, 2010, Behrens and Lafferty 2004). Protection of herbivorous and urchin-feeding fish in no-take reserves on Kenyan coral reefs has been related to increased herbivory, reductions in algal cover, enhanced survival of coral recruits, and enhanced cover of crustose coralline algae (McClanahan and Shafir 1990, McClanahan and Graham 2006, Babcock et al. 2010). In the Bahamas, reserve protection enhanced abundance of parrotfish, increased grazing, reduced algal cover and enhanced coral recruitment (Mumby et al. 2006).
Can such community and ecosystem benefits, known to occur inside reserves, be exported beyond reserve boundaries? Two lines of evidence in the present study are consistent with such a suggestion. Firstly, community composition of predatory fish outside but close to (200-250 m) the Apo reserve became very similar to that inside the reserve over time (Fig. 3). Secondly, a $78 \%$ increase in species richness over 25 years of large predatory reef fish in the fished control site near the southern Apo reserve boundary was associated with a $9 \%$ decline in abundance of prey fish (Fig. 2d). Only one other study has suggested, based on observations at one point in time, that a reserve may have had communitywide effects beyond its boundaries. Guidetti (2006) quantified abundances of predatory reef fish, sea urchins, coralline barrens and macroalgal beds inside and across the boundaries of the Torre Guaceto marine reserve in south-eastern Italy. Inside the reserve predatory reef fish (Diplodus spp.), which preyed on urchins, were abundant, and urchins and barrens were rare. For $2 \mathrm{~km}$ either side of the reserve, there were weak gradients of decreasing density of predatory fish, but fairly strong gradients of increasing prevalence of urchins and barrens. Guidetti (2006) suggested that moderate spillover of the predatory fish, together with their foraging activities from the reserve, was having a community-wide impact beyond the reserve boundaries.

The present study demonstrates the development of export of species richness and community complexity from a NTMR. This export developed over decades and was localized in space (scale hundreds of $\mathrm{m}$ ). It provides an encouraging example, suggesting that export of enhanced biodiversity and ecosystem structure from NTMRs may eventually occur over wider spatial scales (potentially kilometers to tens of kilometers) by recruitment subsidy (Cudney-Bueno et al. 2009, Pecl et al. 2009, Planes et al. 2009), as multiple species recover inside well-protected NTMRs. In the present study, we have documented spillover of species richness of large predatory fish, often considered to be good proxies for healthy marine ecosystems (Worm et al. 2006, Myers et al. 2007). NTMRs may eventually have biodiversity and ecosystem benefits beyond their boundaries.

\section{ACKNOWLEDGMENTS}

This research was supported by a Pew Fellowship in Marine Conservation and the Australian Research Council (ARC) Centre for Coral Reef Studies at James Cook University. R. A. Abesamis, G. P. Jones, and two anonymous reviewers read and made useful improvements to the manuscript.

\section{Literature Cited}

Abesamis, R. A., A. C. Alcala, and G. R. Russ. 2006a. How much does the fishery at Apo Island benefit from spillover? Fisheries Bulletin (U.S.) 104:360-375.

Abesamis, R. A., and G. R. Russ. 2005. Density-dependent spillover from a marine reserve: long-term evidence. Ecological Applications 15:1798-1812.

Abesamis, R. A., G. R. Russ, and A. C. Alcala. $2006 b$. Gradients of abundance of fish across no-take marine reserve boundaries: evidence from Philippine coral reefs. Aquatic 
Conservation: Marine and Freshwater Ecosystems 16:349371.

Alcala, A. C., and G. R. Russ. 2006. No-take marine reserves and reef fisheries management in the Philippines: a new people power revolution. Ambio 35:245-254.

Alcala, A. C., G. R. Russ, A. P. Maypa, and H. P. Calumpong. 2005. A long-term, spatially replicated, experimental test of the effect of marine reserves on local fish yields. Canadian Journal of Fisheries and Aquatic Sciences 62:98-108.

Babcock, R. C., S. Kelly, N. T. Shears, J. W. Walker, and T. J. Willis. 1999. Changes in community structure in temperate marine reserves. Marine Ecology Progress Series 189:125134.

Babcock, R. C., N. T. Shears, A. C. Alcala, N. S. Barrett, G. J. Edgar, K. D. Lafferty, T. R. McClanahan, and G. R. Russ. 2010. Decadal trends in marine reserves reveal differential rates of change in direct and indirect effects. Proceedings of the National Academy of Sciences USA. [doi: 10.1073/pnas. 0908012107]

Behrens, M. D., and K. D. Lafferty. 2004. Effects of marine reserves and urchin disease on southern Californian rocky reef communities. Marine Ecology Progress Series 279:129139.

Bohnsack, J. A. 1998. Application of marine reserves to reef fisheries management. Australian Journal of Ecology 23:298304.

Bohnsack, J. A., and J. S. Ault. 1996. Management strategies to conserve marine biodiversity. Oceanography 9:73-82.

Castilla, J. C. 1999. Coastal marine communities: trends and perspectives from human exclusion experiments. Trends in Ecology and Evolution 14:280-283.

Clark, K. R., and R. N. Gorley. 2006. PRIMER v6: user manual/tutorial. Primer-E, Plymouth, UK.

Côté, I. M., I. Mosquera, and J. D. Reynolds. 2001. Effects of marine reserve characteristics on the protection of fish populations: a meta-analysis. Journal of Fish Biology 59(Supplement A): 178-189.

Cudney-Bueno, R., M. F. Lavin, S. G. Marinone, P. T. Raimondi, and W. W. Shaw. 2009. Rapid effects of marine reserves via larval dispersal. PLoS ONE 4(1):e4140.

Dayton, P. K., E. Sala, M. J. Tegner, and S. F. Thrush. 2000. Marine protected areas: parks, baselines, and fishery enhancement. Bulletin of Marine Science 66:617-634.

Dayton, P. K., S. F. Thrush, T. S. Agardy, and R. J. Hofman. 1995. Environmental effects of marine fishing. Aquatic Conservation 5:205-232.

Edgar, G. J., N. S. Barrett, and R. D. Stuart-Smith. 2009. Reefs protected from fishing transform over decades into conservation features not otherwise present in the seascape. Ecological Applications 19:1967-1974.

Estes, J. A., and O. D. Duggins. 1995. Sea otters and kelp forests on Alaska: generality and variation in a community ecological paradigm. Ecological Monographs 65:75-100.

Gell, F. R., and C. M. Roberts. 2003. Benefits beyond boundaries: the fishery effects of marine reserves. Trends in Ecology and Evolution 18:448-454.

Guidetti, P. 2006. Potential of marine reserves to cause community-wide changes beyond their boundaries. Conservation Biology 21:540-545.

Halpern, B. S. 2003. The impact of marine reserves; do reserves work and does reserve size matter? Ecological Applications 13(Supplement):S117-S137.

Halpern, B. S., S. Walbridge, K. A. Selkoe, C. V. Kappel, F. Micheli, C. D'Agrosa, J. F. Bruno, K. S. Casey, C. Ebert, and H. E. Fox. 2008. A global map of human impact on marine ecosystems. Science 319:948-952.

Hastings, A., and L. W. Botsford. 2003. Comparing designs of marine reserves for fisheries and for biodiversity. Ecological Applications 13(Supplement):S65-S70.

Jackson, J. B. C., et al. 2001. Historical overfishing and the recent collapse of coastal ecosystems. Science 293:629-638.
Jennings, S., and M. J. Kaiser. 1998. The effects of fishing on marine ecosystems. Advances in Marine Biology 34:201-352.

Kaunda-Arara, B., and G. A. Rose. 2004. Effects of marine reef National parks on fishery CPUE in coastal Kenya. Biological Conservation 118:1-13.

Lester, S. E., B. S. Halpern, K. Grorud-Colvert, J. Lubchenco, B. I. Ruttenberg, S. D. Gaines, S. Airamé, and R. R. Warner. 2009. Biological effects within no-take marine reserves: a global synthesis. Marine Ecology Progress Series 384:33-46.

McClanahan, T. R., and N. A. J. Graham. 2005. Recovery trajectories of coral reef fish assemblages within Kenyan marine protected areas. Marine Ecology Progress Series 294: 241-248.

McClanahan, T. R., and B. Kaunda-Arara. 1996. Fishery recovery in a coral-reef marine park and its effect on the adjacent fishery. Conservation Biology 10:1187-1199.

McClanahan, T. R., and S. Mangi. 2000. Spillover of exploitable fishes from a marine park and its effect on the adjacent fishery. Ecological Applications 10:1792-1805.

McClanahan, T. R., and S. H. Shafir. 1990. Causes and consequences of sea urchin abundance and diversity in Kenyan coral reef lagoons. Oecologia 83:362-370.

Micheli, F., B. S. Halpern, L. W. Botsford, and R. R. Warner. 2004. Trajectories and correlates of community change in notake marine reserves. Ecological Applications 14:1709-1723.

Molloy, P. P., I. B. McLean, and I. M. Côté. 2009. Effects of marine reserve age on fish populations: a global metaanalysis. Journal of Applied Ecology 46:743-751.

Mumby, P. J., et al. 2006. Fishing, trophic cascades, and the process of grazing on coral reefs. Science 311:98-101.

Myers, R. A., J. K. Baum, T. D. Sheperd, S. P. Powers, and C. H. Peterson. 2007. Cascading effects of loss of apex predatory sharks from a coastal ocean. Science 315:18461850.

Myers, R. A., and B. Worm. 2003. Rapid worldwide depletion of predatory fish communities. Nature 423:280-283.

Pauly, D., V. Christensen, J. Dalsgaard, R. Froese, and F. Torres. 1998. Fishing down food webs. Science 279:860-863.

Pauly, D., V. Christensen, S. Guenette, T. J. Pitcher, U. Rashid Sumaila, C. J. Walters, R. Watson, and D. Zeller. 2002. Towards sustainability in world fisheries. Nature 418:689694.

Pecl, R. A., M. L. Baskett, T. Tanci, S. D. Gaines, and R. R. Warner. 2009. Quantifying larval export from South African marine reserves. Marine Ecology Progress Series 394:65-78.

Pinnegar, J. K., N. V. C. Polunin, P. Francour, F. Badalamenti, R. Chemello, M. L. Harmelin-Vivien, B. Hereu, M. Milazzo, M. Zabala, G. D'Anna, and C. Pipitone. 2000. Trophic cascades in benthic marine ecosystems: lessons for fisheries and protected-area management. Environmental Conservation 27:179-200.

Planes, S., G. P. Jones, and S. R. Thorrold. 2009. Larval dispersal connects fish populations in a network of marine protected areas. Proceedings of the National Academy of Sciences USA 106:5693-5697.

Rakitin, A., and D. L. Kramer. 1996. Effect of a marine reserve on the distribution of coral reef fishes in Barbados. Marine Ecology Progress Series 131:97-113.

Roberts, C. M. 2007. The unnatural history of the sea. Island Press, Washington, D.C., USA.

Roberts, C. M., J. A. Bohnsack, F. Gell, J. P. Hawkins, and R. Goodridge. 2001. Effects of marine reserves on adjacent fisheries. Science 294:1920-1923.

Roberts, C. M., J. P. Hawkins, and F. R. Gell. 2005. The role of marine reserves in achieving sustainable fisheries. Philosophical Transactions of the Royal Society B 360:123-132.

Russ, G. R. 2002. Yet another review of marine reserves as reef fishery management tools. Pages 421-443 in P. F. Sale, editor. Coral reef fishes, dynamics and diversity in a complex ecosystem. Academic Press, San Diego, California, USA. 
Russ, G. R., and A. C. Alcala. 1996. Do marine reserves export adult fish biomass? Evidence from Apo Island, central Philippines. Marine Ecology Progress Series 132:1-9.

Russ, G. R., and A. C. Alcala. 2003. Marine reserves: rates and patterns of recovery and decline of predatory fish, 1983-2000. Ecological Applications 13:1553-1565.

Russ, G. R., A. C. Alcala, A. P. Maypa, H. P. Calumpong, and A. T. White. 2004. Marine reserve benefits local fisheries. Ecological Applications 14:597-606.

Russ, G. R., B. Stockwell, and A. C. Alcala. 2005. Inferring versus measuring rates of recovery in no-take marine reserves. Marine Ecology Progress Series 292:1-12.

Sala, E., O. Aburto-Oropeza, G. Parades, I. Parra, J. C. Barrera, and P. K. Dayton. 2002. A general model for designing networks of marine reserves. Science 298:19911993.

Sale, P. F., R. K. Cowen, B. S. Danilowicz, G. P. Jones, J. P. Kritzer, K. C. Lindeman, S. Planes, N. V. C. Polunin, G. R. Russ, Y. J. Sadovy, and R. S. Steneck. 2005. Critical science gaps impede use of no-take fishery reserves. Trends in Ecology and Evolution 20:74-80.

Sobel, J. A., and C. P. Dahlgren. 2004. Marine reserves. A guide to science, design and use. Island Press, Washington, D.C., USA.

Stirling, G., and B. Wilsey. 2001. Empirical relationships between species richness, evenness, and proportional diversity. American Naturalist 158:286-299.

Worm, B., et al. 2006. Impacts of biodiversity loss on ocean ecosystem services. Science 314:787-790. 